\title{
Hereditary neuropathy with liability to pressure palsies presenting with sciatic neuropathy
}

\author{
Raffi Topakian, ${ }^{1}$ Sibylle Wimmer, ${ }^{2}$ Barbara Pischinger, ${ }^{3}$ Robert Pichler ${ }^{4}$
}

${ }^{1}$ Department of Neurology, Klinikum Wels-Grieskirchen, Wels, Austria

${ }^{2}$ Institute of Radiology, Wagner-Jauregg Hospital, Linz, Austria

${ }^{3}$ Department of Neurology, Wagner-Jauregg Hospital, Linz, Austria

${ }^{4}$ Institute of Nuclear Medicine, Academic Teaching Hospital Wagner-Jauregg, Linz, Austria

\section{Correspondence to}

Dr Raffi Topakian,

raffi.topakian@hotmail.com

Accepted 28 September 2014

CrossMark

To cite: Topakian $\mathrm{R}$, Wimmer $S$, Pischinger $B$, et al. BMJ Case Rep Published online: [please include Day Month Year doi:10.1136/bcr-2014206883

\section{SUMMARY}

Hereditary neuropathy with liability to pressure palsies (HNPP) is an autosomal-dominant disorder associated with recurrent mononeuropathies following compression or trivial trauma. Reports on sciatic neuropathy as the presenting manifestation of HNPP are very scarce. We report on a 21-year-old previously healthy man who was admitted with sensorimotor deficits in his left leg. He had no history of preceding transient episodes of weakness or sensory loss. Clinical and electrophysiological examinations were consistent with sciatic neuropathy. Cerebrospinal fluid investigation and MRI of the nerve roots, plexus, and sciatic nerve did not indicate the underlying aetiology. When extended electrophysiological tests revealed multiple subclinical compression neuropathies in the upper limbs, HNPP was contemplated and eventually confirmed by genetic testing.

\section{BACKGROUND}

HNPP can be difficult to diagnose in patients with a compression neuropathy but without any history of individual or familial neuromuscular disease. HNPP is usually associated with a heterozygous deletion of the peripheral myelin protein 22 (PMP22) gene on chromosome 17p11.2, but point mutations in the PMP22 gene have been described as well. ${ }^{1}$ HNPP frequently leads to multiple mononeuropathies involving the median, ulnar, radial or, peroneal nerves. Some patients may develop a more generalised neuropathy, while brachial plexopathy is infrequent. ${ }^{2}$ Many affected participants may be unaware of the neuropathy. Our report stresses the importance of a comprehensive electrodiagnostic investigation in unclear cases of sciatic neuropathy.

\section{CASE PRESENTATION}

A 21-year-old man presented to our hospital to obtain a second opinion regarding a 5-week history of a left foot drop and sensory disturbances in his lower leg and foot with only slow and incomplete recovery. An external neurological consultation had considered his symptoms to be related to common peroneal neuropathy due to compression at the fibular neck.

Prior to his actual symptoms the patient had been in excellent health. He denied neurological symptoms in the past or any known familial neuromuscular disorder. According to the patient, he had first taken notice of his symptoms awakening in the afternoon hours after a party night that had involved consumption of alcohol. He remembered a very short-lasting pain in his left groin and buttock immediately after a woman had seated herself on his lap while he had been sitting on the stairs leading to the party club. Pain did not reoccur after that incident. It remained unclear whether he had spent an extended period sitting or lying on the stairs.

On admission, neurological examination revealed sensorimotor abnormalities in his left leg clearly extending beyond the clinical picture of a compressive peroneal neuropathy. On the Medical Research Council (MRC) Scale for grading muscle strength in his left leg, he scored knee flexion $4+/ 5$, toe extensors and foot dorsiflexion $2 / 5$, foot $\mathrm{eV} .3 / 5$ and plantar flexion $4+/ 5$. The ankle jerk was absent in the left leg. He had hypoaesthesia in the lateral aspect of the left lower leg, dorsum of the foot, all toes and anterior part of the sole. Gait was abnormal with left-sided steppage gait. There were no foot deformities. The rest of the neurological examination was unremarkable.

\section{INVESTIGATIONS}

Findings of electrophysiological testing are given in table 1. Nerve conduction studies showed absent sensory nerve action potentials (SNAPs) of the left superficial peroneal nerve, while SNAPs and nerve conduction velocities (NCVs) were normal in the right superficial peroneal and both sural nerves. Compound muscle action potentials, motor NCVs and distal motor latencies were normal in the peroneal and tibial nerves, but $F$ wave latencies were prolonged in the left leg. Needle myography of muscles of the left leg revealed signs of pathological spontaneous activity (positive sharp waves and/or fibrillation potentials) in the tibialis anterior, peronaeus longus, semimembraneous and biceps femoris (short head and long head) muscles, but not in the left iliopsoas, rectus femoris, vastus lateralis, gluteus medius, tensor fasciae latae, adductor longus, gastrocnemius and left paravertebral muscles L4, L5 and S1. He had normal-amplitude polyphasic reinnervation potentials in the left tibialis anterior, peronaeus longus and semimembraneous muscles. In summary, electrophysiological findings suggested a sciatic neuropathy.

Admission creatine kinase serum level was normal. Further work-up including routine blood tests, review of external MRI scans of the lumbar spine, performance of 3-T MRI of the lumbosacral plexus and sciatic nerve and, cerebrospinal fluid examinations were not indicative of the underlying aetiology. Imaging did not reveal clear abnormalities of nerve structures. However, MRI showed 
Table 1 Neurophysiological findings

\begin{tabular}{|c|c|c|c|c|c|c|}
\hline \multicolumn{7}{|l|}{ Nerve conduction studies } \\
\hline \multicolumn{2}{|l|}{ Nerve } & \multicolumn{2}{|l|}{ Normal values } & \multicolumn{2}{|l|}{ Left side } & Right side \\
\hline \multicolumn{7}{|l|}{ Peroneal } \\
\hline \multicolumn{2}{|l|}{ Distal motor latency } & \multicolumn{2}{|l|}{$\leq 5.6 \mathrm{~ms}$} & \multicolumn{2}{|l|}{5.5} & 5.4 \\
\hline \multicolumn{2}{|l|}{ Motor amplitude, ankle } & \multicolumn{2}{|l|}{$\geq 5 \mathrm{mV}$} & \multicolumn{2}{|l|}{7} & 8 \\
\hline \multicolumn{2}{|l|}{ Motor amplitude, fib. head } & \multicolumn{2}{|l|}{$\geq 5 \mathrm{mV}$} & \multicolumn{2}{|l|}{7} & 7 \\
\hline \multicolumn{2}{|l|}{ Motor amplitude, pop. fossa } & \multicolumn{2}{|l|}{$\geq 5 \mathrm{mV}$} & \multicolumn{2}{|l|}{7} & 7 \\
\hline \multicolumn{2}{|l|}{ Motor NCV, leg } & \multicolumn{2}{|l|}{$\geq 40 \mathrm{~m} / \mathrm{s}$} & 45 & & 43 \\
\hline Motor NCV, knee & & $\geq 40 \mathrm{~m} / \mathrm{s}$ & & 53 & & 53 \\
\hline Minimal $F$ wave latency & & $\leq 52 \mathrm{~ms}$ & & 53.8 & & 51.3 \\
\hline Superficial peroneal & & & & & & \\
\hline SNAP amplitude & & $\geq 5 \mu \mathrm{V}$ & & Absent & & 7 \\
\hline Sensory NCV & & $\geq 40 \mathrm{~m} / \mathrm{s}$ & & & & 40 \\
\hline Tibial & & & & & & \\
\hline Distal motor latency & & $\leq 6.0 \mathrm{~ms}$ & & 3.9 & & 4.4 \\
\hline Motor amplitude, ankle & & $\geq 8 \mathrm{mV}$ & & 11 & & 11 \\
\hline Motor NCV & & $\geq 40 \mathrm{~m} / \mathrm{s}$ & & 40 & & 47 \\
\hline Minimal $\mathrm{F}$ wave latency & & $\leq 55 \mathrm{~ms}$ & & 55.2 & & 49.8 \\
\hline Sural & & & & & & \\
\hline SNAP amplitude & & $\geq 10 \mu \mathrm{V}$ & & 16 & & 18 \\
\hline Sensory NCV & & $\geq 40 \mathrm{~m} / \mathrm{s}$ & & 44 & & 45 \\
\hline Femoral & & & & & & \\
\hline Distal motor latency & & $\leq 5.6 \mathrm{~ms}$ & & 4.4 & & 4.0 \\
\hline Motor amplitude & & $\geq 4 \mathrm{mV}$ & & 9 & & 10 \\
\hline Median & & & & & & \\
\hline Distal motor latency & & $\leq 4.2 \mathrm{~ms}$ & & 4.3 & & 4.7 \\
\hline Motor amplitude, wrist & & $\geq 8 \mathrm{mV}$ & & 9 & & 11 \\
\hline Motor NCV, forearm & & $\geq 50 \mathrm{~m} / \mathrm{s}$ & & 59 & & 53 \\
\hline Minimal $\mathrm{F}$ wave latency & & $\leq 29 \mathrm{~ms}$ & & 28.4 & & 28.2 \\
\hline Distal SNAP amplitude & & $\geq 12 \mu \mathrm{V}$ & & 11 & & 20 \\
\hline Sensory NCV, wrist & & $\geq 45 \mathrm{~m} / \mathrm{s}$ & & 42 & & 40 \\
\hline Ulnar & & & & & & \\
\hline Distal motor latency & & $\leq 3.5 \mathrm{~ms}$ & & 3.2 & & 2.6 \\
\hline Motor amplitude, wrist & & $\geq 8 \mathrm{mV}$ & & 11 & & 9 \\
\hline Motor NCV, forearm & & $\geq 50 \mathrm{~m} / \mathrm{s}$ & & 60 & & 51 \\
\hline Motor NCV, elbow & & $\geq 45 \mathrm{~m} / \mathrm{s}$ & & 25 & & 29 \\
\hline Minimal $F$ wave latency & & $\leq 28 \mathrm{~ms}$ & & 32.5 & & 30.5 \\
\hline Distal SNAP amplitude & & $\geq 12 \mu \mathrm{V}$ & & 4 & & 9 \\
\hline Needle myography studies & & & & & & \\
\hline Muscle (left side) & PSA & $\begin{array}{l}\text { MUPs } \\
\text { Amplitude }\end{array}$ & Duration & Polyphasia & IP & \\
\hline Paravertebral L4-S & No & NS & NS & NS & NS & \\
\hline Iliopsoas & No & Normal & Normal & Normal & NS & \\
\hline Rectus femoris & No & Normal & Normal & Normal & NS & \\
\hline Vastus lateralis & No & Normal & Normal & Normal & NS & \\
\hline Adductor longus & No & Normal & Normal & Normal & NS & \\
\hline Tensor fasciae latae & No & Normal & Normal & Normal & NS & \\
\hline Gluteus medius & No & Normal & Normal & Normal & NS & \\
\hline Semimembraneus & Mild & Normal & Increased & Increased & Full activation & \\
\hline Biceps femoris, short head & Mild & Normal & Normal & Normal & Full activation & \\
\hline $\begin{array}{l}\text { Biceps femoris, } \\
\text { long head }\end{array}$ & Mild & Normal & Normal & Normal & Full activation & \\
\hline Tibialis anterior & Mild & Normal & Increased & Increased & Recruitment $\downarrow$, & iring rate $\uparrow$ \\
\hline Peronaeus longus & Mild & Normal & Increased & Increased & Recruitment $\downarrow$, & iring rate $\uparrow$ \\
\hline Gastrocnemius, medial head & No & Normal & Normal & Normal & Recruitment $\downarrow$ & \\
\hline
\end{tabular}

$\uparrow$, Increase; $\downarrow$ Decreased; fib. head, fibular head; IP, interference pattern; MUPs, motor unit potentials; NCV, nerve conduction velocity; NS, not studied; Pathological findings are marked bold; pop. fossa, popliteal fossa; PSA, pathological spontaneous activity (positive sharp waves and/or fibrillation potentials); SNAP, sensory nerve action potential. 


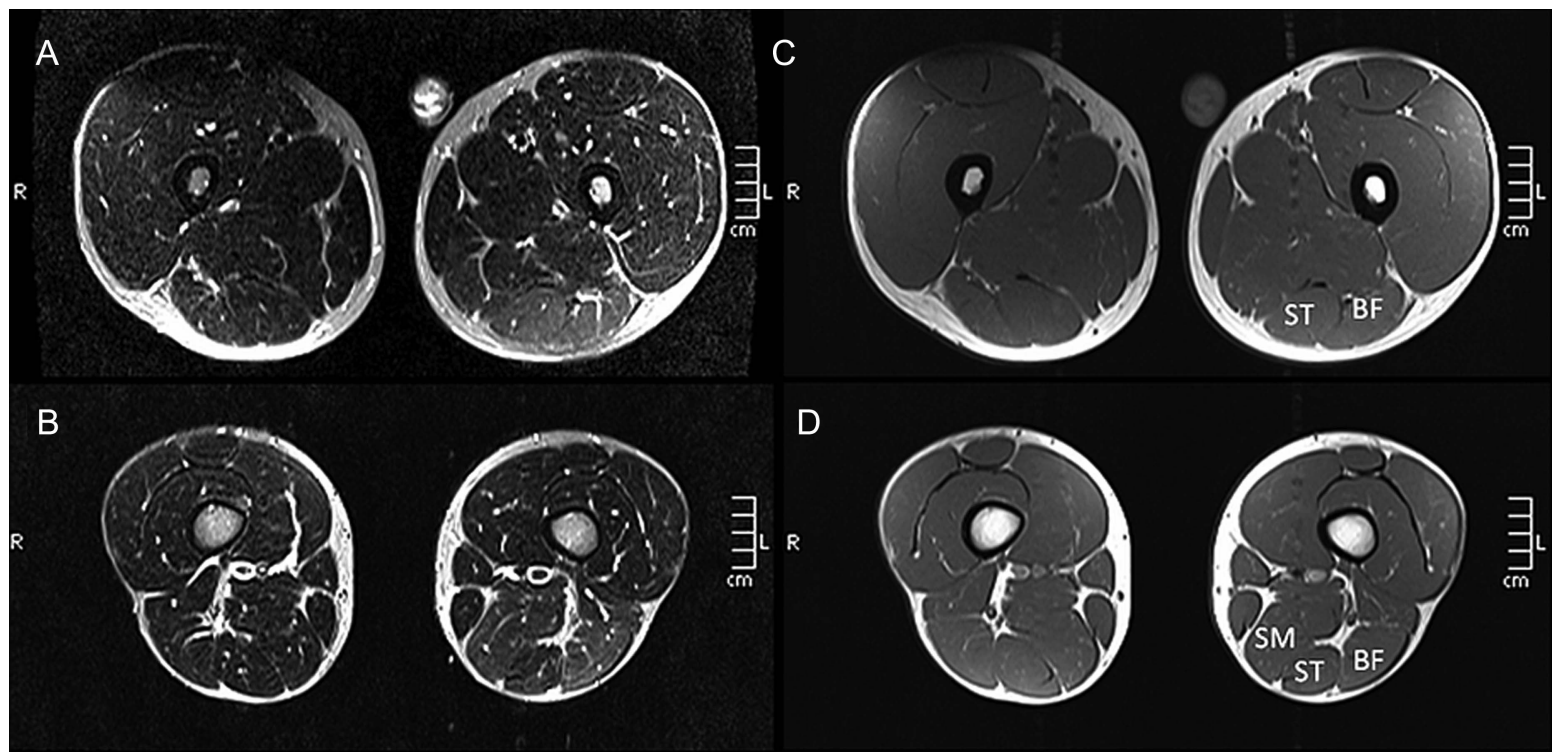

Figure 1 Axial T2 Stir MRI of the thighs (A and B) showing slightly increased signal in the left biceps femoris (BF), semitendineous (ST) and semimembraneous (SM) muscles. Axial T1-weighted MRI at the same levels (C and D) showing normal appearance of the thigh muscles without significant atrophy or fatty infiltration. This pattern is not specific, but consistent with subacute denervation.

slight diffuse oedema in the left semimembraneous, semitendineous, and biceps femoris muscles consistent with subacute denervation in these muscles (figure 1).

The electrophysiological assessment was extended to the upper limbs to look for subclinical clues of a systemic or generalised disease. Nerve conduction studies demonstrated evidence of subclinical bilateral sensorimotor carpal tunnel syndrome and bilateral sensorimotor ulnar neuropathy at the elbow. We considered the differential diagnosis of HNPP with respect to the electrophysiological evidence of multiple subclinical entrapment neuropathies in the upper limbs and the history and clinical symptoms indicative of an incomplete, slowly improving sciatic neuropathy following compression trauma.

Genetic testing revealed a heterozygous deletion of the complete PMP22 gene verifying HNPP.

\section{DIFFERENTIAL DIAGNOSIS}

The clinical syndrome of sciatic neuropathy may sometimes be mistaken for polyradiculopathy, lumbosacral plexopathy or common peroneal neuropathy due to compression at the fibular neck. Among others, aetiologies of sciatic neuropathy include infections (f.e. psoas muscle abscess), sacroiliitis, surgery, haematomas, tumours of nerve or surrounding tissue structures, vascular causes (f.e. iliac artery occlusion), gynaecologic causes (f.e. endometriosis), radiotherapy and compression trauma.

\section{TREATMENT}

The patient received physical therapy and electrotherapy for several weeks to improve motor function in his left leg.

\section{OUTCOME AND FOLLOW-UP}

Further slow improvement of motor functions was observed on clinical follow-up approximately 3, 6 and 12 months after the first symptoms. However, improvement was incomplete after 12 months with residual left foot dorsiflexion MRC $4+/ 5$ and unobtainable left ankle jerk. The patient received information about typical triggering factors for pressure palsies. Family members were invited for clinical examination and genetic counselling.

\section{DISCUSSION}

The identification of the cause of sciatic neuropathy in an individual patient may set a challenging task for the clinician. ${ }^{3}$ In our patient, the differential diagnosis of HNPP was contemplated with respect to neurophysiological evidence of multiple subclinical compression neuropathies in the upper limbs and a history suggestive of compression trauma of the left sciatic nerve. The value of thorough electrodiagnostic testing to establish the diagnosis of underlying HNPP has been described before in a patient presenting with brachial plexopathy. ${ }^{4}$ Neurophysiological examination in HNPP often shows typical findings of a demyelinating neuropathy in non-symptomatic limbs. ${ }^{5}$ In our patient, an axonal component of the sciatic neuropathy on top of a primary demyelinating pathomechanism was indicated by the neurophysiological finding of some abnormal spontaneous activity in several muscles. Interestingly, 3-T MRI was consistent with slight denervation oedema in several muscles of the left posterior thigh, but did not depict clear-cut abnormalities of nerve structures.

Unusual presentations of HNPP are rare. Our literature search identified only very few reports on patients with HNPP presenting as sciatic neuropathy. ${ }^{67}$

\section{Learning points}

- When encountering a patient with unclear sciatic neuropathy, a thorough neurophysiological testing is needed and may lead to consideration of HNPP.

- In sciatic neuropathy due to HNPP, 3-T MRI of the sciatic nerve and muscles of the leg may not be indicative of the underlying aetiology.

- Recovery from mononeuropathies in participants with HNPP may take months and be incomplete.

- To verify HNPP, genetic testing is needed and usually reveals a heterozygous deletion of the peripheral myelin protein 22 gene.

- Management of HNPP patients relies primarily on the prevention of factors triggering nerve compression. Genetic counselling should be offered to family members. 
The management of patients with HNPP should be carried out along published guidelines. ${ }^{8}$ It is of paramount importance that patients and family members are carefully counselled and that factors triggering nerve compression and palsies are avoided.

Contributors RT is responsible for drafting and revising the manuscript. SW, BP and RP were critically involved in the acquisition of clinical and imaging data and the revision of the manuscript.

Competing interests None.

Patient consent Obtained.

Provenance and peer review Not commissioned; externally peer reviewed.

\section{REFERENCES}

1 Chance PF, Alderson MK, Leppig KA, et al. DNA deletion associated with hereditary neuropathy with liability to pressure palsies. Cell 1993;72:143-51.
2 Ørstavik K, Skard Heier M, Young P, et al. Brachial plexus involvement as the only expression of hereditary neuropathy with liability to pressure palsies. Muscle Nerve 2001;24:1093-6.

3 Distad BJ, Weiss MD. Clinical and electrodiagnostic features of sciatic neuropathies Phys Med Rehabil Clin N Am 2013:24:107-20.

4 Bulusu S, McMillan HJ. A report of hereditary neuropathy with liability to pressure palsy (HNPP) presenting with brachial plexopathy: the value of complete electrodiagnostic testing. Am J Electroneurodiagnostic Technol 2011;51: 183-90.

5 Pareyson D, Solari A, Taroni F, et al. Detection of hereditary neuropathy with liability to pressure palsies among patients with acute painless mononeuropathy or plexopathy. Muscle Nerve 1998;21:1686-91.

6 Lynch JM, Hennessy M. HNPP presenting as sciatic neuropathy. J Peripher Nerv Syst 2005;10:1-2.

7 Ichikawa K, Nezu A. Hereditary neuropathy with liability to pressure palsies in childhood: report of a case and a brief review. Brain Dev 2005;27:152-4.

8 Dubourg 0, Mouton P, Brice A, et al. Guidelines for diagnosis of hereditary neuropathy with liability to pressure palsies. Neuromuscul Disord 2000;10:206-8.

Copyright 2014 BMJ Publishing Group. All rights reserved. For permission to reuse any of this content visit http://group.bmj.com/group/rights-licensing/permissions.

BMJ Case Report Fellows may re-use this article for personal use and teaching without any further permission.

Become a Fellow of BMJ Case Reports today and you can:

- Submit as many cases as you like

- Enjoy fast sympathetic peer review and rapid publication of accepted articles

- Access all the published articles

- Re-use any of the published material for personal use and teaching without further permission

For information on Institutional Fellowships contact consortiasales@bmjgroup.com

Visit casereports.bmj.com for more articles like this and to become a Fellow 